\title{
Carlos Hernán Sosa, La novela gauchesca de Eduardo Gutiérrez. Prensa, discurso judicial y folletín en la génesis de una literatura popular. Buenos Aires, Katatay, 2020, 550 páginas
}

\author{
Soledad Martínez Zuccardi
}

Cita sugerida: Martínez Zuccardi, S. (2021). [Revisión

del libro La novela gauchesca de Eduardo Gutiérrez.

Prensa, discurso judicial y folletín en la génesis de una

literatura popular por C. H. Sosa]. Orbis Tertius, 26(33),

e205. https://doi.org/10.24215/18517811e205

Dada la relativamente abultada bibliografía crítica existente acerca de la gauchesca argentina - y en particular acerca de las novelas de Eduardo Gutiérrez (en la que se cuentan estudios importantes como los ya clásicos de Jorge B. Rivera o el más reciente de Alejandra Laera, por citar un par de ejemplos)—, se podría pensar que no hay mucho más que decir sobre el asunto. Este libro de Hernán Sosa, editado de modo impecable por Katatay, demuestra lo contrario. A partir de una escritura clara y reflexiva, atenta a precisiones y matices, La novela gauchesca de Eduardo Gutiérrez. Prensa, discurso judicial y folletín en la génesis de una literatura popular lleva las investigaciones sobre el tema a un grado de complejidad, completitud y profundidad hasta el momento no alcanzado, a la vez que despeja prejuicios y corrige algunos errores.

En una suerte de acto de reparación, el libro exige volver a pensar el lugar de Gutiérrez y de su obra en la literatura argentina. La tan transitada novela del ' 80 - modélicamente representada por los nombres de Lucio V. López, Miguel Cané, Eugenio Cambaceres, Lucio V. Mansilla—, a partir de esta investigación no puede ya relegar al margen el de Gutiérrez. Los folletines del autor, que prefieren matrices discursivas no canónicas, se destacan con la singularidad de su gesto contestatario frente a los carriles hegemónicos de la producción literaria que imponía la cultura letrada de Buenos Aires a comienzos de la década de 1880. A la vez, el novedoso perfil de escritor construido por Gutiérrez, como "gestor de un proyecto literario filo popular —sólido y sostenido en el tiempo-, amparado en una apuesta profesional por su oficio” (16), echa por tierra la visión reduccionista de los autores del ' 80 como desganados y oligárquicos gentlemen. En la dedicatoria misma del volumen aquí reseñado hay una toma de posición que revela una comprometida sensibilidad 
respecto de los sectores populares: "los pobres, los iletrados y los parias" que "también forman parte de los discursos y las prácticas de la literatura” (9) y a los que Hernán Sosa dedica su estudio. Desde ese compromiso y esa sensibilidad, Sosa logra brindar una perspectiva nueva, libre de visiones estereotipadas y preconceptos, acerca de los alcances de lo popular en Gutiérrez.

Partiendo de la noción bajtiniana de la novela como género capaz de nutrirse de las discursividades sociales, el libro explora tres matrices discursivas en la génesis de la novela gauchesca de Gutiérrez: la prensa, el discurso judicial y el folletín (los tres elementos anunciados ya en el título del volumen). En estas matrices se apoya la sólida estructura del estudio: a una primera sección dedicada a los planteos preliminares siguen tres grandes partes, destinadas precisamente a las prácticas discursivas periodísticas, a los discursos provenientes del ámbito judicial y a los aportes literarios del folletín. Esta estructura se imbrica también con la hipótesis general, según la cual el proceso de elaboración de las primeras novelas de Gutiérrez sigue un derrotero donde la escritura se inicia con ciertas readecuaciones del discurso periodístico y judicial, y avanza hacia un mayor desprendimiento de dichas discursividades, a medida que el género folletín se cimenta como tal hacia 1880 .

Luego de un conjunto de consideraciones sobre la novela y los géneros literarios — articulado desde la siempre vigente perspectiva de Mijaíl Bajtín-, la primera parte caracteriza a Gutiérrez como un profesional de la literatura, traza un completo recorrido por los antecedentes de la novela gauchesca, y examina en detalle las distintas ediciones de las novelas del autor, tomando en cuenta la manipulación operada sobre los textos por algunos editores así como las ediciones clandestinas. Propone además un esquema de la abundante producción novelística de Gutiérrez, cuyo "corpus total” aún no ha sido establecido. Prueba de ello son dos folletines descubiertos y rescatados por Sosa: Juan Carnaval y El crimen de la calle Reconquista, que no habían sido antes reconocidos como parte de la obra del autor y quedan a partir de ahora incorporados a ese corpus.

La segunda parte se adentra ya en una de las tres matrices discursivas consignadas: el periodismo. Examina la historia de La Patria Argentina, diario de los hermanos Gutiérrez donde Eduardo publica sus folletines, y analiza el perfil editorial amplio del periódico, su posición política — defensora del centralismo porteño y opositora a la administración roquista-, y, entre otros aspectos, sus rasgos distintivos respecto de otros diarios porteños de la época. Son de particular lucidez las reflexiones sobre los lectores del diario. Se trata de agudas especulaciones sobre los procesos de lectura que solo pueden recomponerse, siguiendo el paradigma indicial de Carlo Ginzburg, a partir de informaciones parcializadas e indicios dispersos. Por dar un ejemplo, a partir de la consideración del precio del ejemplar del diario y del valor de las suscripciones - cotejada con datos estadísticos sobre el salario de un trabajador promedio-, Sosa conjetura que para un obrero el diario era un objeto suntuario. Un dato no menor, que permite discutir la reiterada hipótesis de que Gutiérrez alcanzó el éxito editorial gracias al consumo de las franjas sociales populares. Por el contrario, parece haber sido el lector acomodado, que podía comprar el diario, quien se encontraba en condiciones de ocupar el rol de lector de Gutiérrez (si bien no se descarta que el público popular haya accedido a la lectura en forma grupal o "de oídas"). Se arriba así a una interesante conclusión: fue en definitiva la elite letrada porteña — a la que Gutiérrez pertenecía y frente a la cual se avergonzaba de su profesión- la que terminaría convalidando, con la compra del diario y con su lectura, el orden popular que gobernaba discursivamente ese mundo otro que la literatura del folletín devolvía.

En el estudio en detalle de las particularidades discursivas de La Patria Argentina, se consideran ciertas secciones del diario, como el fait divers y el "caso célebre", que proporcionan "posibles embriones narrativos" aptos para el folletín. El libro rescata tres "protofolletines” construidos sobre la estructura del caso célebre, que permiten examinar la prehistoria del género gauchesco en La Patria Argentina. Aunque editados de manera anónima, Sosa atribuye su autoría a Gutiérrez. El análisis revela los procesos de cruces y préstamos entre las noticias que se "literaturizan" y los folletines que se pautan según modelos de la crónica periodística, demostrando las utilidades que la prensa brindó, con su batería de usos discursivos, en los orígenes de la novela gauchesca. Dicho planteo se opone claramente a la tendencia a aislar periodismo de literatura e ignorar cómo desde la prensa se origina la novela gauchesca. Se orienta, por el contrario, en la disposición a "aceptar que 
una nueva literatura puede surgir desde un espacio periodístico", según las palabras de Susana Rotker citadas por Sosa.

Una vez establecido este origen periodístico, se analiza el proceso de paulatino desplazamiento de la discursividad periodística a la literaria. Una instancia fundamental en este proceso es la firma de Un capitán de ladrones en Buenos Aires (1879), que parece dar cuenta del momento en que Gutiérrez percibe la originalidad del giro de su texto y decide, por primera vez, firmar. Aparecen enfatizados allí los recursos tendientes a propiciar la discursividad literaria, como la alusión a otros textos (es el caso de El Conde de Montecristo de Alexandre Dumas, con el cual el relato de Gutiérrez establece permanentes comparaciones, en una especie de puesta en abismo), la autorreferencialidad en la construcción del personaje, el gesto paródico, el manejo tendencioso de la intriga, la destreza y la soltura en la agilización del relato. Este proceso aparece potenciado por las declaraciones del propio Gutiérrez, quien defiende su primer texto firmado como una "especie literaria”, arrogándose para sí el rol de autor de literatura y fomentando en esa dirección la estabilización de su figura en el marco de las incipientes regulaciones del circuito de producción literaria porteña en la época.

En sintonía con la hipótesis general del proceso de gradual prescindencia de los géneros discursivos no literarios, sustituidos por una mayor contribución de las estrategias literarias del folletín, la tercera parte examina la incorporación del discurso judicial en las novelas. En un pulcro trabajo con las fuentes documentales, el contenido de las causas penales protagonizadas por Juan Moreira y Hormiga Negra es confrontado con los folletines homónimos. Sosa revela que Gutiérrez tuvo acceso directo al expediente judicial contra Moreira, y que fue ese el material que tomó como base para su novela y no las completas crónicas periodísticas que salieron durante los años que duró el proceso (1869-1879). Una muestra del paulatino abandono del discurso judicial es el "maquillaje" que realiza Gutiérrez del personaje, a quien construye como un héroe de cuño romántico, en la línea de la figura del judío errante que busca justicia del folletín de Eugène Sue. Reacomoda los hechos presentados en las causas judiciales con el fin de victimizar a Moreira y adecuarlo así tanto a las necesidades del folletín como a la conclusividad de la novela gauchesca (por cuanto ambas líneas necesitan un sujeto incomprendido, "buena gente" aunque empujado al crimen). Estas transformaciones se orientan también a la búsqueda de una recepción empática de los lectores, en un circuito de lectura periódica en la que la adhesión del lector supone réditos para el diario.

En aras de esa búsqueda de construcción de un héroe en tanto víctima acorralada por la adversidad, Gutiérrez suaviza la brutalidad de los crímenes y los justifica, en una suerte de redención de la figura del asesino. Este fino trabajo de recomposición novelesca del héroe involucra distintos aspectos, desde la apariencia física a su relación con la política. Para Sosa, en este último punto Gutiérrez disimula con menor maestría las falencias del orden corrupto que el protagonista contribuye a consolidar. Ante la imposibilidad de negar la relación de Moreira con un sistema político electoral corrupto, emergen las contradicciones de su figura, que en este aspecto es tanto víctima como victimario. En el caso de Hormiga negra, publicado a fines de 1881, el tiempo transcurrido desde la publicación de Juan Moreira (1979-1880) parece propiciar un mayor desprendimiento de los pre-textos discursivos judiciales ante el imperio de estrategias narrativas más propicias para el folletín (los empleos autorreferenciales de la puesta en abismo, el humor, la intertextualidad en el pastiche y la caricatura, la parodia, se van constituyendo como nuevo repertorio procedimental). La novela gauchesca se desplaza así hacia modalidades menos constreñidas al verismo y más apta a las libertades estilísticas que suele priorizar la literatura, si bien la alusión a las fuentes documentales no desaparece nunca y se cristaliza como fórmula literaria en los textos de Gutiérrez.

Por último, la sección cuarta, dedicada a las contribuciones específicas del folletín en las novelas del autor, constituye un significativo aporte a la poco trabajada historia del folletín porteño. Da cuenta de la rapidez con la que las estrategias del folletín van impregnando discursivamente la narrativa de Gutiérrez y enfatiza en los enlaces con la tradición literaria de los modelos europeos: Alexandre Dumas, Eugène Sue, Émile Gaboriau, entre otros. Revela además la importancia concedida por La Patria Argentina a la literatura y en particular al folletín, que proporciona los mayores réditos al diario y termina convirtiéndose en el principal factor de 
sostén económico de la empresa familiar. Dice mucho al respecto que el diario sobreviva muy poco tiempo tras la orfandad producida por el alejamiento de Gutiérrez hacia La Crónica, y deba cerrar en 1883.

Si en las secciones anteriores del libro se privilegian desde un punto de vista diacrónico las transformaciones que dan lugar al nacimiento de la novela gauchesca de Gutiérrez, esta última parte focaliza ya en determinados folletines como Juan Moreira, El tigre de Quequén, Juan Cuello, Santos Vega, Hormiga Negra. Se examinan las representaciones de la historia nacional, que en el corpus aparecen aggiornadas, con el propósito de generar mayor identificación en los lectores, al momento contemporáneo a la escritura. Así, desde un reposicionamiento de esa historia como lugar de divertimento, el rosismo es desmitificado a partir del humor y la ironía. En contradicción con la interpretación previa de Sarmiento, Alberdi, Echeverría o Gorriti, los sectores acomodados son implícitamente acusados de cómplices del rosismo en las novelas de Gutiérrez, y siempre desde la perspectiva de un marginal, víctima popular del régimen. También se explora la figura del gaucho y el proceso de criminalización de esa figura (como Santos Vega, de instinto asesino, pendenciero, cuchillero de primera línea, adicto a los duelos), así como la amistad entre gauchos que reproduce la pareja de Fierro y Cruz, rozando subrepticiamente el vínculo amoroso. En cuanto a la relación del gaucho con el indio (ambos excluidos sociales), este último es visto contemplativamente por los personajes de Gutiérrez, quienes asumen modos relacionales inclusivos que distan de la visión segregacionista de Fierro (así, Moreira disfruta la vida en la toldería donde satisface todos sus apetitos).

Todas las intervenciones de las palabras de los gauchos perseguidos de las novelas del autor funcionan como ideologemas contestatarios al régimen sociopolítico que imponía el proceso de estabilización y modernización del estado argentino. Desde el lugar de un sujeto marginal, formulan una visión desacralizadora del proyecto liberal sociopolítico del '80. Ello provocó intensos rechazos en el incipiente campo literario y favoreció la acumulación de todo un compendio de recepciones adversas (citadas en la Introducción del libro). Sin embargo, en las representaciones analizadas se cuelan las contradicciones ideológicas de Gutiérrez y sus subliminares acuerdos con los hombres del '80. El personaje de Moreira está atravesado por la contradicción y reúne aspectos ideológicamente irreconciliables. Víctima y victimario, tiene su momento honrado y a la vez se erige en la contrapartida insalvable del gaucho regenerado de La vuelta del Martín Fierro, que ingresa al nuevo sistema agroexportador del país, encarnando el ejemplo del correcto camino de redención de un miembro del sector popular disidente. Moreira, en cambio, resiste su ingreso a dicho sistema mediante el delito. Hijo mimado entre los personajes de Gutiérrez, Moreira encarna la moderna imagen de la contradicción y la figura del héroe que no puede adecuarse a su destino y a su situación característica de la novela moderna.

La novela gauchesca de Eduardo Gutiérrez. Prensa, discurso judicial y folletín en la génesis de una literatura popular traza la arqueología de un género sin dejar de considerar arista alguna. Se trata de un libro insoslayable a la hora de pensar la historia de la gauchesca, del folletín y de la novela en la Argentina, y de reflexionar en torno a cuestiones tales como las relaciones entre literatura y otros discursos sociales, la figura del escritor, los circuitos de producción periodística/literaria, los intereses económicos, la incidencia del lectorado, en un momento crucial para la construcción de la literatura argentina. 